\title{
LEGAL ASPECTS OF COMPUTER USE IN MEDICINE
}

\author{
RoY N. FreED*
}

INTRODUCTION

On July 5, 1967, a computer in Washington, D.C., analyzed electrocardiograms of patients in France and returned interpretations within thirty seconds. ${ }^{1}$ That feat, which utilized a communications satellite, dramatized the intimate involvement of medicine with the current interrelated technological revolutions in electronic information processing and communications. Since the rendering of medical care largely is a series of information processing functions, increasingly those functions will be delegated to computers with varying degrees of responsibility. ${ }^{2}$ Being alerted to that development, laymen and lawyers alike promptly become curious about the legal rights and liabilities of the various participants in the process of using computers in medicine. These participants include not only patients and doctors but also hospitals and other suppliers of specialized data processing services, manufacturers of computers and other equipment, system designers, and programmers.

Imaginative doctors and medical engineers foresee great benefits to patients from the use of the new technology. They are working actively to develop a wide variety of applications. ${ }^{3}$ Equally imaginative plaintiffs' lawyers, on the other hand, undoubtedly will develop new applications of tort liability theory to secure damages for harm suffered by patients. Those lawyers might inquire, for example, along the following, very diverse lines: Can a doctor escape liability to a patient injured by his using a computer system to administer anesthesia? Is it legally safe for a doctor to fail to use a computer diagnosis system or simulation system for pretesting treatment? May the operator of a diagnosis system cater to laymen? Do hospital charity patients have a right of privacy that guarantees freedom from routine treatment by medical students when computer-operated teaching dummies are available? May a patient harmed by a flaw in a computerized intensive care monitor sue the system manufacturer on the basis of strict liability?

This article considers some representative legal considerations related to uses of

- B.S. 1937, LL.B. I940, Yale University. Division Counsel, Computer Control Division, Honcywell Inc., Framingham, Mass. Member of the Massachusetts, Connecticut, and Pennsylvania bars. Contributor to legal and engineering periodicals.

The opinions expressed in this article are entirely those of the author and are not to be attributed to Honeywell Inc.

${ }^{1}$ N.Y. Times, July 6,1967 , at 37 , col. 8.

See Davis, Computers in Medicine, INT's Sci. \& Trchnorocy, Dec. 1966, at 40.

'See generally id.; Baruch \& Barnett, Joint Venture at Massachusetts General, Daramation, Dec. 1965, at 29; Caceres, Computer Analysis of Medical Signals, id. at 34; Greanias, The Computer in Medicine, id. at 24; Kleinmuntz, Clinical Information Processing, id. at 40; Shaw, Rx for Medical Instrumentation; Realism, Patience, Communication, Elecrronics, July 10, 1967, at 96; Spinrad, Automation in the Laboratory, 158 Scr. 55 (1967). 
computers in medicine that are reasonably to be anticipated. In developing the topic, attention is given first to the nature of the related computer and communications technologies as they are involved with medicine generally. Then, successively but with no indication of relative significance, some of the most likely computer uses in medicine are described in sufficient detail to provide factual background for legal review, and the legal impact of each use is explored to suggest how the various questions might be approached, if not resolved. Since the medical applications discussed are just being introduced or developed, no direct precedents are available. ${ }^{4}$

Fortunately, it is not necessary for this purpose to prove the technical feasibility of the various applications identified or to describe them accurately or in full detail. In view of the importance of computers to medicine and the momentum already developed for their use, it is reasonable to assume that the ingenuity of doctors and engineers will make the suggested applications practical in the not-too-distant future. Much, if not all, of their legal significance can be appreciated from the brief descriptions provided.

It is hoped that this study will dispel any unwarranted concerns over legal barriers to efficient use of computers in medicine that might inhibit the adoption of needed systems and will suggest how any genuine handicaps can be overcome. Its purpose also is to encourage regard for pertinent legal considerations in system planning and operation so that each computer use will have as sound a legal foundation as possible and affected legal rights will be respected.

This article will not cover the legal aspects of the use of computers in medicine peripherally to keep doctors' accounts, as research tools (rather than clinical devices) in medical laboratories, or to maintain central medical records for all persons.

\section{I}

\section{Computer Technology}

It is essential to understand a number of general characteristics of computer technology in order to identify the legal aspects of its use in medicine and to suggest how they might be treated..$^{5}$ Those characteristics include not only how the devices work but also how their use is made available.

Essentially, computers are machines for processing information. They do so by performing mathematical operations and by making comparisons with predefined standards. In general, they can be set up to carry out any information processing operations that people know how to do and hence can describe in full detail. For this purpose, the operations must be reduced to their elementary logical steps. Most digital computers are general purpose machines, similar to typewriters, and can

\footnotetext{
"For a similarly anticipatory discussion, see Wasmuth, Homi \& Hale, Hyperbaric Medicine and Law, I4 Clev.-Mar. L. Rev. 300 (1965).

IIn view of the extremely dynamic nature of the technology, it should be recognized that the description provided, however general, well might be made inaccurate at any time by changes that occur continually.
} 
use their abilities to carry out a wide variety of very different tasks, frequently doing so practically simultaneously.

Where feasible, computers generally are used as elements of larger systems rather than merely as advanced, independent calculating machines. In such systems the computer controls other equipment, processes and reports on information it receives, and assembles and analyzes large quantities of data. Computers can do these things because they are basically different from all other machines in that they work automatically in accordance with programs stored within themselves. The programs tell the computers how to cope with various circumstances that might be encountered during their operation. Only the instructions given will be performed. If an unanticipated situation occurs, at the present state of the art, the computer cannot cope with it without external assistance, but it can be instructed to call for such help. Computers also can be caused to adjust themselves, with considerable versatility, as the conditions they are working with change.

The programming is reflected in records often called "software documentation." That documentation normally will contain statements of the instructions and the circumstances under which they will be given, that can be understood, in large measure, by a nonspecialist. Since programs are changed frequently to accommodate new situations or newly acquired knowledge or to correct deficiencies, ideally documentation is kept up to date and logs of program usage are maintained. Hence, it generally is possible to find out much about what a particular computer could have done or probably actually did in the past.

Computers are analogous to human beings in that they can receive messages in various forms from the outside world, can store facts and instructions, can manipulate information to do arithmetic and to make comparisons, and can communicate to the outside world by many different media. They can handle input information on almost the entire range of physical phenomena, including color, temperature, pressure, viscosity, speed, weight, shape, and time, for example, as well as alphabetic, numeric, written, and audible material. With the ability to compare for magnitude and identity, they can make prearranged types of decisions or conclusions. They can manifest their decisions or conclusions by operating devices (such as valves, pumps, motors, and heaters), by activating alarms, and by printing words and numbers or displaying them on a cathode ray tube.

Computers function more rapidly and accurately than people. They operate at speeds measured in billionths or smaller fractions of a second. And they normally carry out their instructions reliably, without suffering from fatigue, distractibility, and other human frailties.

While computers can report their observations and conclusions more efficiently than people in terms of speed, accuracy of detail, and volume of material, they do not have the automatic memory of humans. They make no record of what they have observed or done unless directed to do so. When so instructed, however, they 
can record not only on magnetic tape and similar machine-readable media but also in such visual forms as written text, charts, and graphs.

Also, as distinguished from people, computer systems repeat exactly what they did before if they are rerun or otherwise encounter the identical situation. Similarly, a computer specialist generally can describe, with a substantial degree of certainty, what a computer system must or would have done, if he is told the elements of the system and the inputs at the time in question.

Where a computer is used as an element in a system rather than only as an advanced calculating machine, the entire system first is described or designed by a person knowledgeable primarily in the particular subject matter, who specifies the nature and extent of action to be taken and the circumstances in which it should occur. Then, the design is reduced to a program by a programmer, who normally is adept at some aspect of that general skill. The design might exist in the records in narrative form or as a flow diagram.

Error rates in computer system operations generally are substantially lower than in nonmechanized activities. Moreover, errors that do occur usually are caused by people, either when introducing information into the system or in designing or programming the system, rather than by the operation of the computer and related equipment. The risk at input is greatest when people communicate their observations of phenomena to computers and least when accurate sensing devices send such information directly to the machines. Considerable error prevention is achieved by the "debugging" of programs in advance and by including in programs and the machines themselves measures that will detect the possibility of error and lead to corrective action. Normally, so-called benchmarks are selected as the critical items to be tested to see if the system is working correctly. However, debugging many systems challenges the ingenuity of man and usually is not foolproof, because of the extreme difficulty of anticipating all possible situations that might confront the particular computer system as it operates.

Although complete failures are unavoidable in machine systems, techniques are available to minimize their effects through standby arrangements, manual backup measures, and fail-safe alarms. Furthermore, many computers have power interrupt features that automatically record the status of operations when electricity is lost. As indicated, it is the distinct trend to use computers as integral elements in continually operating systems, rather than merely as processing machines run intermittently when batches of information are collected. In the newer approach, the computers are said to be on line, working in real time. There also is a tendency to set up integrated systems, in which as many related tasks and operations as possible are combined in a single system, to be carried out routinely and without interruption. With increasing frequency, closed loop systems are set up where appropriate to provide fully self-regulating control of processes, such as chemical production and petroleum refining. In such systems, messages from sensors trigger adjust- 
ments necessary to maintain proper operation. Furthermore, in on-line, real-time systems, provision usually is made to treat people, as well as the machines, as elements of the system so that they are in the information flow as sources and recipients and can interact regularly. Similarly, by utilizing on-line communication links, such as provided by public or private telephone service, computer systems achieve greater capabilities and can function over long distances, as evidenced by the international electrocardiogram analysis project described at the beginning of this article.

Examples of computer applications outside medicine indicate the direction of mechanization in that field. For example, in an on-line, real-time system, information is gathered on pertinent phenomena as it is available; this information is processed by the computer promptly upon receipt and in accordance with rules; and decisions are made by the computer and action is taken by other elements of the system at the direction of the computer. Computers are used in industry at various levels of responsibility. Some run single machines or entire factories automatically; others monitor processes and warn personnel when dangerous conditions exist; and still others merely record or log data as operations progress. The three functions can be combined. Also, computers are used to simulate various activities in order to perform tests or provide a learning experience without the the need either to create a prototype or to carry out the actual operation. Some simulators have a physical resemblance to the real thing. For example, an aircraft or spacecraft simulator for teaching purposes will have a cockpit and controls. Other simulations are performed solely with mathematical models manipulated entirely within the computer. Such simulations can be used to pretest physical phenomena, such as the strength of an aircraft component in use. Computers also are used to check out complicated devices, such as space rockets ready for flight, and present their reports in words and numbers on a cathode ray display. It should take little imagination to identify counterparts of these applications in medicine.

The opportunity to use computers is expanding rapidly as more machines become available, as specialized application programs are created, and as the cost of computing time decreases. Computer use costs less because the prices of computers are being reduced at the same time that their capacities and speeds increase. Use costs are lower, too, because it is possible, in so-called time-sharing systems, to buy only the amount of time needed, on demand. Also, charges for use frequently reflect economies achieved in operating, on a fee basis, specialized computer services using either a particular file of information or a group of programs, such as credit verification or the making of engineering calculations, that can serve many customers.

Since computer systems are assemblages of computer central processing units, peripheral equipment (input-output and memory devices), system designs, programs, and other items, they can be created by any entity prepared for the task. Such an entity could be, for example, not only a system manufacturer that buys 
computers outside or a computer manufacturer itself but also a system operator. System designing and programming might be done either by one of those entities or by an independent contractor specialist.

It is hoped that this brief review of computer technology will contribute to a better appreciation of the legal aspects of the specific uses of the devices in medicine that are discussed in the remainder of this article. Those uses include diagnosis assistance, direct participation in therapy, simulations for teaching and pretesting treatment, and hospital record-keeping with the capability of checking on the propriety of prescribed medications.

\section{II}

\section{Diagnosis by Computer}

\section{A. Nature of Computer Diagnosis Systems}

With their remarkable ability to compare extensive data with pre-established norms, computers will be utilized widely to assist doctors in making diagnoses. Two different types of diagnosis systems can be expected.

Systems will be set up, on an operating basis, first to interpret relatively limited physical data on particular body functions or conditions, such as electrocardiograms and samples of blood or other body fluids. In that area, the computer systems probably will be regarded primarily as clinical laboratory instruments. With their restricted scopes, those laboratory systems can provide fairly conclusive opinions on the specific matters for which they will be designed, much as a specialist would render, only considerably faster.

Later, systems undoubtedly will be offered to suggest possible diagnoses based on more extensive symptom data. The great complexities of the general diagnostic process undoubtedly will preclude directly usable machine opinions based on such data. Instead, the output, being highly probabilistic, will serve merely as memory reinforcers for doctors, by indicating possible causes and other symptoms to be looked for. Actual diagnoses in those cases still will be made by doctors who will use the output along with other data. Despite all their very real limitations, good general diagnostic systems nevertheless could have the substantial merit of at least alerting their users to unusual medical problems that doctors ordinarily would not think of. Being replicative, they could be interrogated at a later date to show what they would have responded if they had been given particular symptoms.

In both types of systems, persons highly skilled in the particular medical subject matter will specify precisely how the computers will carry out their logical operations and what information they will have in their memories. That activity constitutes the designing of the system. The machine systems will be no better, as regards the technical information they contain, than the persons contributing that information are proficient in their special fields, although they might be 
superior at least in part in the way they function because of their ability to assimilate more data at one time.

In order to minimize exposure to error through sample switching and similar misfortunes, efforts undoubtedly will be made wherever possible to provide input information directly from the patient to the diagnostic computer, such as can be done with electrocardiograms. Comparable protection can be achieved where the doctor submits symptoms on line to the computer.

At the present state of the art, particularly the cost of acquiring and operating computers, it is likely that business concerns, hospitals, or professional associations, rather than practicing doctors as such, will operate computers for diagnostic purposes." The systems usually can be economical only if they serve many users. For many applications, users can be located at a substantial distance from the site of the computer. Many systems probably will be run under the direction of doctors.

Initiative to use computer diagnostic systems that are offered would have to come primarily from doctors, who probably will be the ostensible customers of the services in most cases. In view of the nature of medical practice, they have to be convinced that the assistance is technically sound and that using it would be consistent with their best interests and would not entail undue professional, legal, or economic risks. To a lesser extent, patients might influence their doctors to resort to such services in the same way they induce consultations with specialists.

It is reasonable to expect that the use of diagnostic systems will be provided on a fee basis, since each use is separate and is identifiable, at least by the doctor, with a particular patient. With the precedent of fee charges for clinical laboratory work, the costs for such computer analyses undoubtedly will be passed on to patients routinely, without any awkwardness. This will be facilitated by the fact that the availability of computer services will be recognized fairly readily as socially beneficial. For example, computers will make available the skills of specialists in areas where they are not located and could result in the rendering of medical services at lower costs. Where fees of the outside service are paid by the patient directly, the operator necessarily will receive the patient's name, a fact relevant to the patient's right of privacy.

The handling of the costs of more general diagnostic aids probably will be more involved. Passing on of charges to patients could introduce professional complications and have resulting legal ramifications affecting a doctor's duty to use such systems. Doctors very likely will be reluctant in most cases to admit, by incurring charges for patients or by seeking reimbursement from them, that they have used

\footnotetext{
'The selection of the entity that will own and operate computer systems of the types discussed in this article will be influenced by the tax laws. Hospitals enjoying tax exemptions would have an economic advantage in that respect over taxpaying entities. A bill has been introduced in Congress to give hospital exemptions to cooperative data processing organizations serving hospitals and composed of hospitals. S. 2315, 90th Cong., Ist Sess. (1967). Other factors also might be influential. An alleged attempt by organized pathologists to monopolize medical laboratories is cited in note 24 infra.
} 
a general computer diagnosis system on their own initiative. They will believe that patients normally expect their doctors to be competent to make substantially all diagnoses without outside assistance. ${ }^{7}$ On the other hand, doctors will not want to use such a service and absorb the charges as part of their overhead, even if they could be recouped through increased fees. If doctors do not attempt to have their patients pay the computer diagnosis fees directly, they probably will give the operators some code designations for the patients, rather than their names, to protect confidentiality.

Incidentally, it also is possible that computer systems that deliver recommended therapy routines and similar information to doctors will be operated. Where such systems have the same qualities as those suggesting general diagnoses, their legal aspects should be comparable. In some instances the closer analogy may be to patient simulation by computer, a subject discussed further on. ${ }^{8}$

\section{B. The Doctor}

\section{Malpractice Liability}

As both actual and potential users of available computer diagnosis systems, doctors are exposed to malpractice liability to their patients. The test of such liability is the failure to use the degree of care and professional skill normally exercised by doctors in the same field of medicine practicing in a similar locality. ${ }^{9}$ However, it would not necessarily be improper to use a treatment technique acceptable to a respectable minority of the profession in the area; ${ }^{10}$ indeed, doctors are legally obliged to keep reasonably abreast of medical progress. ${ }^{\text {II }}$ On the other hand, a doctor must make a referral to another doctor properly qualified if the patient's condition requires care beyond his competence or for which he lacks necessary equipment. ${ }^{12}$ Consideration now will be given to how these general rules might apply to both types of diagnosis systems.

During the time in which the output of a particular laboratory diagnosis system is accepted by the profession on a par with the opinions of medical specialists, it could be an exercise of due professional care for a doctor to rely upon an erroneous opinion produced by that system, if the error was not obvious to a person with the

\footnotetext{
${ }^{7}$ It is unlikely that the increasingly frequent press descriptions for laymen of medical computer systems will dispel this consideration. In such a description, the following observation was made: "No one suggests that a computer will replace the physician in diagnosing diseases, but it is quite clear that it will be a great aid to a doctor's memory." Boston (Mass.) Globe, Nov. I4, 1967, at 30, col. I.

${ }^{8}$ See pp. 697-700 infra.

${ }^{0}$ E.g., Worster v. Caylor, 231 Ind. 625, Iro N.E.2d 337 (I953); Zoterell v. Repp, I87 Mich. 3I9, 153 N.W. 692 (1915).

${ }_{10}$ Gielskie v. State, Io App. Div. 2d 47I, 200 N.Y.S.2d 69I (1960), aff'd mem., 9 N.Y.6.2d 834, I75 N.E.2d 455 (196r).

${ }^{11}$ Reed v. Church, I75 Va. 284, 293, 8 S.E.2d 285, 288 (I940) (dictum).

12 Tvedt v. Haugen, 70 N.D. 338,294 N.W. I83 (1940); Annot., 132 A.L.R. 392 (I94I). "A physician should seek consultation ... in doubtful or difficult cases . . ." AMA. PRincrpLes of Medical Ethics $\$ 8$ (Rev. I957) [hereinafter cited as AMA EthIcs], reprinted in D. Louiseli \& H. Williams, Trial of Medical Malpractice Cases, para. 2.04, at ig n.8 (r960).
} 
proper degree of skill.13 However, if flaws in such a system become known in the profession, reliance on its output while its reputation is in question could be the basis for a malpractice claim against the doctor using it. In view of a doctor's duty to make a referral or consultation to provide necessary professional skill, ${ }^{14}$ there might be situations in which that duty would be satisfied by use of such a computer diagnosis system as an alternative to resort to a specialist. Furthermore, if no qualified specialist is reasonably available but a computer system is, conceivably even by telecommunications, then failure to use the service could constitute malpractice, assuming that such a failure was the proximate cause of the harm suffered. Of course, where the proper input data are missing, such a malpractice claim would be handicapped by the difficulty of proving what the service would have stated if used.

Since the output of more general computer diagnosis assistance systems will constitute merely suggestions intended to reinforce the memory of the doctor who actually will make the diagnosis, there probably can be no legal claim by a patient based on any reliance by his doctor on erroneous output. The diagnosis is made by the practicing doctor, not the computer system, and any malpractice stems from the doctor's own failure to meet the applicable test of competence. Were the doctor to rely wholly upon the computer diagnosis, he would be substituting it for his own judgment, an act of delegation he ordinarily could not properly make. On the other hand, if the system is acknowledged to reflect high professional quality, its output consistent with an erroneous diagnosis of a doctor using it might be persuasive evidence to support his defense that he used adequate professional skill. ${ }^{15}$ It might be argued that such output, properly offered, is equivalent to the testimony of other doctors. ${ }^{16}$ But, conversely, if a doctor makes an erroneous diagnosis despite his receipt of system output suggesting the actual problem, it is possible that such receipt would bolster a malpractice charge, thereby creating a legal situation worse for him than if he had not consulted the system.

If a doctor does not use a general diagnosis system and makes an erroneous diagnosis, the mere failure to seek machine aid probably would not constitute compensable malpractice unless the system is acknowledged by the profession to be useful, unless it is economical to use or the patient agrees to pay the cost, and unless the patient has a rare problem that would have been suggested in response

\footnotetext{
${ }^{18}$ Cf. Pilgrim v. Landham, 63 Ga. App. 45I, II S.E.2d 420 (I940); In re Johnson's Estate, I45 Neb. 333, I6 N.W.2d 504 (1944).

14 Joint Comm'n on Accreditation of Hospitals, Standards for Hospital Accreditation 5 (Dec. I965).

${ }_{15}$ Cf. Redwood v. Raskind, 49 Tenn. App. 69, 350 S.W.2d 4r. (I96I), noted in 25 GA. B.J. 103 (1962).

${ }^{10}$ In some states, published material written by recognized experts is admissible in malpractice actions as proof of facts or as opinions. E.g., Stoudenmeier v. Williamson, 29 Ala. 558 (1857); MAss. ANN. LAws ch. 233, $\$ 79$ C (Supp. I966); NEv. REv. STAT. $\$ 51.040$ (I957). Since they specifically cover published treatises, periodicals, books, and pamphlets, statutes providing for the admissibility of such evidence probably would not provide a basis for the admission of computer output.
} 
to symptoms the doctor actually identified or a reasonably competent doctor would have observed. If a doctor misdiagnoses a common condition, any malpractice would be the result of his personal error rather than his failure to use a computer system. Again, the fact that the system output would have included the correct diagnosis could be evidence of lack of skill if the system enjoys general professional respect. As indicated, what the system would have told the doctor generally can be determined by giving it the symptoms, and making allowances for any system changes in the interim. In many cases, the doctor's records on the patient will disclose the symptoms he noted and relied upon.

Liability very likely would exist for avoidable harm if a physician failed to use an acceptable system requested by a patient who offered to pay its cost unless he expressly indicated that he would not do so. ${ }^{17}$ If a doctor is so requested by a patient and indicates that he will use a computer system but then does not, he probably would be liable, although more likely for fraud rather than malpractice. ${ }^{18}$ However, if he expressly refuses, he would not be liable unless it was professionally acceptable to use the service and the patient had no genuine opportunity to secure another doctor. ${ }^{19}$ A patient who had such an opportunity to switch and failed to use it could be held to have consented to the doctor's course of action and to have assumed the risk of the doctor's not consulting the outside service. ${ }^{20}$

Since imposition of malpractice liability usually requires proof through the defendant's fellow professionals, ${ }^{21}$ injured patients will have a strong incentive, where possible, to sue persons who might be liable on more easily proved grounds of negligence or strict liability. Those persons might include diagnosis system and component manufacturers and operators.

\section{Insurance}

Most of the legal exposure of doctors to their patients related to computer diagnosis systems appears to be covered by malpractice insurance, which generally encompasses all damage because of injury arising out of malpractice, error, or mistake in rendering or failing to render medical services. ${ }^{22}$ However, some situations might be beyond the scope of that coverage. For example, an intentional failure to comply with a promise to a patient to consult a service might be characterized as

\footnotetext{
58.

${ }^{17}$ Ethical principles require a doctor to seek consultation upon request of the patient. AMA ETHICs

${ }^{18}$ See Berkson v. Chandler, 5 Ill. App. 2d 583, I26 N.E.2d 389 (1955).

${ }^{10}$ Abandonment can constitute malpractice. Carroll v. Griffin, 96 Ga. App. 826, ror S.E.2d 764 (1958); D. Louiseld \& F. Witliass, Triat of Medical Malpractice Cases, para. 8.08 (x960, Supp. 1966) [hereinafter cited as LouIserL \& WIIIIAMs].

${ }^{30}$ See Champs v. Stone, 74 Ohio App. 344, 58 N.E.2d 803 (1944).

${ }^{22}$ This rule is subject to exception where res ipsa loquitur applies. See generally Comment, Medical Malpractice-Expert Testimony, 6o Nw. U.L. REv. 834 (1966); Comment, The Application of Res Ipsa Loquitur in Medical Malpractice Cases, id. at 852.

${ }^{22}$ See generally LoUISELI \& Writams, para. 20.03; Hirsh, Insuring Against Medical Professional Liability, I2 VAND. L. REv. 667 (I959).
} 
fraud or some other type of actionable conduct, in which case the doctor would have to explore the availability of a different kind of insurance. ${ }^{23}$

\section{Antitrust}

Since some computer laboratory diagnosis systems will be performing functions that otherwise would have been performed by doctors, many doctors might resent the competition, especially at a lower price. ${ }^{24}$ If doctors are stimulated by such an attitude to use joint action to affect the prices charged or to exclude the service entirely, they could violate the federal antitrust laws if their steps interfere with interstate commerce or commerce within the District of Columbia. ${ }^{25}$ They could also violate comparable state antitrust laws.

Similarly, some doctors might want to discourage resort to general computer diagnostic assistance services lest their use become the custom in the area and hence a general professional responsibility, especially if the charges have to be absorbed by doctors. Again, concerted effort might constitute an antitrust breach. ${ }^{20}$

On the other hand, an attempt to capitalize economically on such a service by means of kickbacks or comparable techniques, such as was alleged to have been made by some opthalmologists with respect to dispensing opticians, ${ }^{27}$ also could violate those laws. Of course, arrangements under which doctors contributing to the design of computer diagnosis systems would secure compensation for that work measured by system use normally would escape such a legal risk.

Just as medical associations are expected to maintain responsible oversight over the professional competence of practitioners in their localities, ${ }^{28}$ so they very likely will take an interest in the operations of computer systems performing medical functions, particularly the laboratory-type systems which make diagnoses themselves. $^{29}$ Even if there are federal clearance requirements for such machine systems, that would not necessarily eliminate the proper continuing interest of medical associa-

\footnotetext{
${ }^{23}$ Nevertheless, a malpractice insurer probably would be well advised to assume the defense of a suit against the insured doctor for intentional harm, Gray v. Zurich Ins. Co., 65 Cal. $2 d 263,54$ Cal. Rptr. ro4, $4 \mathrm{rg}$ P.2d I68 ( 1966 ); but the doctor would risk the strong incentive of the attorney so defending to resist any effort to amend the complaint to cover malpractice.

${ }^{24}$ In United States v. College of Am. Pathologists, Civil No. 66Ciz53 (N.D. Ill., filed July 7, 1966), an attempt by pathologist members of the defendant association to monopolize the commercial medical laboratory business in the United States is alleged.

${ }^{26}$ American Medical Ass'n v. United States, 317 U.S. 519 (1943).

${ }^{26}$ See id.

${ }^{27}$ United States v. White-Haines Optical Co., I950-I95I Trade Cas., para. 62,882 (S.D. Ohio 1951) (consent decree). See also Hearings on Physician Ownership in Pharmacies and Drug Companies Before the Subcomm. on Antitrust and Monopoly of the Senate Comm. on the Judiciary, 88th Cong., 2d Sess. (1964), concerning the practices of doctors who prescribed drugs manufactured by firms in which they owned substantial interests.

${ }^{28}$ AMA ETHICs $\S_{4}$; see Comment, Medical Societies and Medical Service Plans-From the Laty of Associations to the Law of Antitrust, 22 U. CHr. L. REv. 694, 695 (1955).

${ }^{29}$ See FTC v. Raladam Co., 283 U.S. 643,653 (I93I). By way of comparison, the Amercian Bar Association, through its Special Committee on Electronic Data Retrieval, is considering measures to protect users of computerized systems for searching for legal literature, which probably will entail primarily disclosure of information on the details of each system.
} 
tions. Manifestations of such interest, however, must fall within the scope of reasonable activities of a truly professional nature as distinguished from joint efforts primarily to protect the economic position of doctors.

\section{The System Operator}

The business entities operating computer diagnosis systems probably would be exposed to claims of patients or doctors only where clinical laboratory systems are involved. It seems unlikely that general systems will be offered, for some time to come, if ever, that do any more than jog the doctor's memory. In that respect, they will have much the same function as books. Hence, defects in those general systems would not be the proximate cause of injury to patients. The cause, instead, would be the doctor's lack of skill. The remaining discussion of operator liability relates only to clinical laboratory systems unless indicated otherwise. ${ }^{30}$

\section{Negligence}

Unless the system operator is an institution enjoying charitable or governmental immunity when performing the service, ${ }^{31}$ it probably would be liable directly to a patient injured through its fault. Lack of privity through the ostensible interposition of the doctor should constitute no problem in view of the widespread elimination of that requirement. If required, privity probably would be found to exist where the patient is billed for the service, despite the fact that he personally neither ordered it from the operator nor received the output directly.

Patients might choose to sue system operators for negligence in a number of situations. For example, where it was reasonable for a doctor to rely upon an erroneous machine laboratory diagnosis, the operator, on the other hand, well might have been careless in running a system that would produce such a result, because it knew or should have known of deficiencies in information content or machine operation. However, as suggested under the next subheading, it might be proper to alter the test of negligence where harm is attributable to the medical information used in the system.

It is entirely possible that a hospital might be negligent for neither having a laboratory computer system nor using one available outside. That could be the case where such a system is significantly more rapid or accurate than the traditional analytical tools and is economical to acquire and its use would have avoided harm.

\section{Strict Liability}

Since system operators might be exposed to strict liability, patients injured by their output (generated on the basis of proper input) and not handicapped by the

\footnotetext{
${ }^{30}$ See generally Mills, Malpractice and the Clinical Laboratory, ${ }_{44}$ Scr. 638 (1964), for a review of legal exposure of clinical laboratories.

${ }^{31}$ See generally Loursels \& WILIIANs, paras. 17.07-.57, for summaries of the condition of the immunity doctrine in the fifty states and the District of Columbia; Horty, The Status of the Doctrine of Charitable Immunity in Hospital Cases, 25 OHro ST. L.J. 343 (1964).
} 
disappearing requirement of privity or by charitable or governmental immunity certainly would prefer to sue them on that ground rather than their doctors, whose liability rests only on fault. Such a suit against the system operator might be based on the argument that the erroneous output that caused the harm is a defective product manufactured by the operator in accordance with methods it chose. The analogy might be drawn to a poorly designed or manufactured product that caused injury. Even though the computer output is only nominally physical and really is information, nevertheless it is delivered to be used and can cause as much harm in the hands of the doctor as a tangible instrument. The fact that the doctor using the system induces the output of a laboratory diagnosis system (by submitting the input in the form of a sample of body fluid or the like) and hence causes it to be made to order does not detract from the analogy.

Along these lines, if the output of the service were considered to be "goods" under the Uniform Commercial Code, ${ }^{32}$ the operator could be liable for breach of warranty of merchantability. ${ }^{33}$ Since the patient will pay for the laboratory work, he probably is the "buyer" entitled to the rights and remedies provided by the Code, and his doctor would be acting as his agent in dealing with the system operator. ${ }^{34}$

In defense, it might be contended that functioning of the laboratory diagnosis system is equivalent to the work of a doctor making the same type of diagnosis and hence should be subjected, with respect to the medical information stored within it, to a test of legal liability no more stringent than is that of the doctor or to at least the test of ordinary negligence. In practice, many system reports probably would be signed by a doctor. That argument probably would be stronger (very likely merely on an ad hominem basis) if made by a nonprofit organization rather than a commercial company. Similarly, it might be contended that the system output is analogous to the report of a noncomputerized medical laboratory that relies primarily on the conclusions of people.

\section{Operational Formalities}

The creation of laboratory reports by computer would not obviate formal require-

\footnotetext{
${ }^{82}$ UnIform Commercisi Code $\$ 2$-I05. However, \$2-r02 provides that "this Article applies to transactions in goods." Thus, the operator would argue that although his report fell within the definition of "goods," the transaction was essentially a contract for services and not, therefore, subject to the Code provisions.

${ }^{33}$ UNiform COMmercial CODE $\$ 2$-3I4. It should be recognized that courts have been reluctant to imply warranties in connection with services of professionals and hospitals. Lovett v. Emory Univ. Inc., CCH Prod. Lias. Rep., para. 5836 (Ga. Ct. App. 1967) (supplying blood not a sale); Perlmutter v. Beth David Hosp., 308 N.Y. 100, 123 N.E.2d 792 (1954) (supplying blood not a sale); Dorfman v. Austenal Inc., 3 UCC ReP. 856 (N.Y. Sup. Ct. I966) (supplying surgical pin to patient not a sale); Texas State Optical, Inc. v. Barbee, CCH Prod. Liab. Rep., para. 5837 (Tex. Civ. App. 1967) (fitting of contact lenses by optometrist). However, it has been held more recently that hospitals are subject to strict liability, including such warranties. Jackson v. Muhlenberg Hosp., 96 N.J. Super. 314, 232 A.2d 879 (L. Div. 1967) (delivery of blood; no liability for hepatitis because of specific disclaimer and fact that blood was not unreasonably dangerous in view of risk of shock if it were not supplied).

${ }^{34}$ Jackson v. Muhlenberg Hosp., 96 N.J. Super. 314, 232 A.2d 879 (L. Div. 1967).
} 
ments such as signatures, ${ }^{35}$ and they should not be overlooked. Where reports are transmitted directly in machine language, it is impractical to use signatures. Even where they are sent as print-outs and hence can be signed, it is burdensome to have to preserve the signed reports since the working record will be in machine language. It can be anticipated that many such requirements will be changed to accommodate new types of systems. ${ }^{36}$

Substantially more extensive requirements might exist, such as licensing, demonstrations of proficiency, and maintenance of copies of reports for inspection. ${ }^{37}$

\section{Injury to Doctor's Reputation}

Although attention has been focused on compensation for harm to patients, doctors also might suffer injury from a defective computer system and seek damages from the system operator. If a doctor's professional reputation is tarnished by his proper reliance on the output of a laboratory diagnosis system that was operated carelessly, the operator could be required to reimburse him for the loss. ${ }^{38}$ Since it would be unreasonable to rely on the suggestions of a general diagnosis system, no similar legal claim could be pressed against its operator.

\section{Unauthorized or Unethical Practice of Medicine}

So long as the computer diagnosis system operator restricts its clientele to doctors, it probably could withstand any charge of unauthorized or unethical practice of medicine. Normally, operators would prefer to limit their customers in that manner. Exposure to such a charge, however, is not entirely remote. Traditional medical laboratories, which analyze body fluids and give opinions that are comparable to the output of computer systems, have escaped such a challenge at least in part because they perform functions most doctors do not want to perform themselves. But some computer systems will do desirable work that has been done by doctors, such as interpreting electrocardiograms, thereby stimulating possible resentment on essentially economic grounds. If a system operator is a doctor licensed in the state in which he functions and not a corporation ${ }^{30}$ and if he does not advertise, ${ }^{40}$ he would probably be safe in even the most hostile environment.

\footnotetext{
${ }^{g 5}$ JoInt Coms'n on Accreditation of Hospitals, supra note $\mathrm{I}_{4}$, at 4 (clinical pathology, X-ray, and tissue reports must be signed).

${ }^{B B}$ For example, it is understood that the Department of Health of the City of New York is waiving the requirement that clinical laboratory test results be stated on the requisition form. This problem is further discussed at pp. 700-02 infra. Incidentally, it is possible for computer output to state the input that stimulated it as well as the results.

${ }^{37}$ E.g., ILL. Rev. Stat. ch. III 1/2, \$\$ 622-103, 623-10I, 624-103, 627-106 (1965).

${ }^{88}$ Stott v. Johnston, 36 Cal. $2 d 864,229$ P.2d 348 (I95I) (damage to goodwill of painting contractor by inferior paint made by defendant was actionable).

${ }^{B D}$ See People v. United Medical Serv., Inc., 362 Ill. 442, 200 N.E. 157 (I936); Annot., I03 A.L.R. 1240 (1936).

'0 N.Y. Enuc. LAw $\$ 6514$ (Mckinney Supp. I967) (advertising or soliciting grounds for revocation of license to practice medicine); ILI. REv. STAT. ch. III $1 / 2, \$ 629-10 I$ (c) (1965) (clinical laboratory may not advertise to the public).
} 
However, an operator well might be tempted to try to serve the undoubtedly large market represented by laymen interested in their own medical problems. In doing so, it probably would encounter the suggested legal barriers to corporate practice of medicine and to the advertising of medical or clinical laboratory service; moreover, in some states, clinical laboratories may serve only physicians and other qualified persons. ${ }^{41}$ But even if these handicaps do not exist, the venture might be attacked for fostering self-medication. In this respect, a violation of medical ethics might be found in the making of diagnoses for laymen without any intention of undertaking treatment. Normally, doctors who limit their practice to diagnosis are specialists serving only other doctors. Similarly, it might be against public policy as facilitating self-medication, by laymen, of nonminor illnesses. Self-treatment is not legally protected as is self-representation in court, witness the restriction on the dispensing of many medications without a doctor's prescription. It should be noted that medical laboratories generally do not serve laymen directly, although probably largely to avoid offending doctors, who are their major customers. However, some laboratories do cater to laymen in connection with tests for pregnancy, which is a unique medical condition. Where other medical tests are performed for laymen, such as chest $\mathrm{X}$-rays, they usually are primarily screening procedures intended to detect persons with suspicious conditions who should see a doctor for proper diagnosis. ${ }^{42}$

\section{Defamation of Patient}

Computerized clinical laboratories probably are as vulnerable as their nonmechanized counterparts to defamation charges for reporting erroneously that patients have venereal and other "loathsome" diseases. ${ }^{43}$ However, both are shielded by the same qualified privilege where publication is made to the types of persons who reasonably would be expected to receive the information, since those reports rarely, if ever, are made with actual malice. ${ }^{44}$ Laboratories normally are not exposed to such charges as a practical matter because their reports go only to doctors, and patients are unaware of them unless the doctors make disclosure, thereby triggering legal action against themselves. ${ }^{45}$ Although patients have been unsuccessful in contending that dictation of an erroneous laboratory report to a stenographer is unprivileged publication, ${ }^{46}$ not even such disclosure occurs where a computer actually prints out the

\footnotetext{
${ }^{41}$ E.g., III. Rev. STAT, ch. III 1/2, $\$ 627$-10I (1965).

${ }^{12}$ Franklin, Medical Mass Screening Programs: A Legal Appraisal, 47 Cornerz L.Q. 205 (1962).

${ }^{48}$ Shoemaker v. Friedberg, 8o Cal. App. 2d 9rr, 183 P.2d 3 18 (1947). The reader may find humorous the appearance in this ultramodern context of the quaint old doctrine that to misrepresent another's health so flagrantly is libel per se.

"1d. See also Berry v. Moench, 8 Utah 2d 19x, 33I P.2d 814 (I958); Mass. ANN. Laws ch. II2,

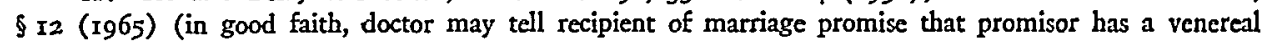
disease).

${ }^{46}$ These were the circumstances in Shoemaker v. Friedberg, 80 Cal. App. 2d 9xx, 183 P.2d 318 (1947).

${ }^{\circ}$ Id.
} 
report or, as might be done in the future, sends it by telephone to be printed out in the doctor's office.

\section{The System Manufacturer}

\section{r. Negligence}

An injured patient might want to sue a diagnosis system manufacturer, even on the grounds of negligence, if the doctor was not negligent or if the system operator enjoys charitable or governmental immunity ${ }^{47}$ or just because he feels that the manufacturer is the most vulnerable target on practical grounds. That manufacturer brings together and sells, or less frequently leases, the complete package consisting of the computer and other hardware, the system design, and the programs, and probably created one or more of those elements itself. It would be liable to the patient for fault, and, again, lack of privity should not be a handicap. If the offending element of the diagnosis system is something the manufacturer bought outside rather than made itself, there might be a question whether it was negligent in using that element. ${ }^{48}$

\section{Strict Liability}

As usual, it would be most advantageous to the injured patient to impose strict liability on the system manufacturer for harm from a defective system, where privity is not a factor. ${ }^{49}$ That application of that theory probably is closer to the commonly accepted one than the similar approach ${ }^{50}$ with respect to output of the system operator. Since the thing causing the harm includes a computer, which is a machine, the computer system more closely resembles the traditional manufactured product than does mere computer output. In fact, the cause of the erroneous output, insofar as the manufacturer is concerned, most likely would be the system design or the program, with the result that the computer system would suffer from defective design, a well recognized basis for strict liability. ${ }^{51}$ Of course, under the normal rule, strict liability cannot be escaped even if due care was exercised in using a defective part acquired elsewhere. ${ }^{52}$

As suggested briefly in discussing the system operator's liability, diagnosis and other medical types of computer systems might be unique because of the special nature of the stored information with which they work, and consequently might

\footnotetext{
${ }^{47}$ See Sevits v. McKiernan-Terry Corp., 264 F. Supp. 810 (S.D.N.Y. r966), which held that a member of the U.S. Navy could sue the manufacturer of a component of a vessel manufactured by the federal government.

${ }^{18}$ Pabon v. Hackensack Auto Sales, Inc., 63 N.J. Super. 476, I64 A.2d 773 (App. Div. I960).

${ }^{10}$ Goldberg v. Kollsman Instrument Corp., i2 N.Y.2d 432, 240 N.Y.S.2d 592, I9I N.E.2d 8I (I963) (passenger may sue aircraft manufacturer for breach of implied warranty of fitness for contemplated use by virtue of faulty design or manufacture).

${ }^{0}$ Discussed at pp. $685-86$ supra.

${ }^{61}$ Goldberg v. Kollsman Instrument Corp., I2 N.Y.2d 432, 240 N.Y.S.2d 592, I91 N.E.2d 8x (I963).

${ }^{53}$ Ford Motor Co. v. Mathis, 322 F.2d 267 (5th Cir. I963); Vandermark v. Ford Motor Co., 6I Cal. 2d 256, 37 Cal. Rptr. 896, 39I P.2d I68 (r964).
} 
deserve a special liability rule. Just as the malpractice standard of care is less stringent than ordinary negligence, presumably because of the difficulty of applying medical knowledge, so computer systems applying that same knowledge well might be spared the rigors of strict liability to that extent. ${ }^{53}$ It would not seem reasonable that the substitution of machine systems for doctors in order to provide better or less expensive medical care ipso facto should enlarge patients' legal rights. A doctrinaire approach to strict liability in this area might inhibit the introduction of needed machine aids in medicine.

If strict liability is applicable, the fact that input is submitted by the doctor to the system for it to work on should not detract from any such liability. Each such submission represents use of the system for its intended purpose, much like driving an automobile or eating packaged food. If the system operator has bought a complete system, its role relative to a design defect is essentially nominal, similar to that of the retailer of packaged food. Its own responsibility would involve, in fact, its failure to have preventive maintenance done on the computer or to have corrections made for system design or programming errors uncovered.

\section{E. The System Designer and the System Programmer}

\section{Negligence}

If not protected by the privity requirement, the business entity that designed or programmed the system could be liable for negligence to a patient harmed by its error. 54

\section{Strict Liability}

The designing or programming business entity might be exposed to strict tort liability to injured patients if its defective design or program caused the diagnosis system to inflict the harm..$^{55}$ Its work product could be considered to be the offending element in a defective machine sold or leased by the system manufacturer.

\section{III}

\section{Performance of Medical Procedures by Computer}

\section{A. Nature of Computer Treatment Systems}

Computers will play a direct, major role in the performance of many medical treatment procedures, as distinguished from the diagnostic uses discussed above. In therapy, a great advantage of computers is their ability to operate on-line, in real

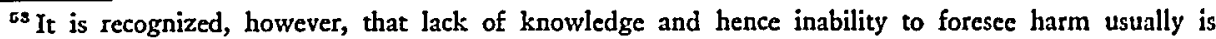
no defense to strict liability. Gottsdanker v. Cutter Iaboratories, I82 Cal. App. 2d 602, 6 Cal. Rptr. 320 (1960); Green v. American Tobacco Co., 154 So. $2 d$ 169 (Fla. 1963). Contra, Lartigue v. R.J. Reynolds Tobacco Co., 317 F.2d I9 (5th Cir. 1963).

os See Katz, Negligence in Design: A Current Look, 1965 Iss. L.J. 5.

${ }^{E S}$ It might be that the component manufacturer's implied warranty of fitness and merchantability applies only if the producer of the major item is immune to suit. Cf. Sevits v. McKiernan-Terry Corp., 264 F. Supp. 810 (S.D.N.Y. I966).
} 
time, and, whenever feasible, in a closed loop, to supplement unique human judgment with machine reliability, data processing capacity, persistence, and speed. Such medical applications are comparable to factory process control uses in industry, because the living human, for purposes of this discussion, is as much an operating system as is a chemical factory or a railroad. Of course, human functioning is much more complex than any nonanimal system and presents difficult problems of measurement and control, especially in closed loop applications. Computer systems will be used at various levels of responsibility. For example, such systems might be used to record details they observe on the conditions of patients (data logging); to monitor the functioning of patients whenever observation is required, especially during medical procedures (particularly operations) and in postoperative situations; and to carry out medical procedures, such as the administration of anesthesia or medications. Each higher order approach can, and probably will, include functions of the lower ones.

Substantially all computer treatment systems will involve considerable manmachine interaction. Each such element will perform the functions it can do best, and both will operate in close coordination. If the computer merely logs data, it probably will display the information for medical personnel. If the system does monitoring, it will call for professional help when the patient requires it. On the other hand, if the machine performs medical procedures, the doctor or nurse will be in close proximity to intervene as needed.

Incidentally, it is feasible to use data logging and monitoring systems on patients who are at a substantial distance from the computer itself. Patients at home or even performing their normal activities can be served by devices that pick up signals of body functions and transmit them by radio. They and their doctors could even be warned by the computer of impending danger. Although the distances that can be spanned are not as great as that in the international electrocardiogram project described earlier, the application of remote monitoring probably will be very useful.

Treatment systems will have a greater variety of hardware than most diagnosis systems. They will include many different sensors and transducers to pick up and convert input signals from different parts of the patient's body and output means to give audible and visual alarms and to report current conditions and trends. For the latter purpose, cathode ray tube displays that can project graphs as well as words and numbers will play a major role.

Treatment-type computer systems are attractive because they can perform many important functions better than people. ${ }^{56}$ For example, they can check on many aspects of a patient's condition constantly and can compare their observations with pre-established norms. They also can record the data as well as announce it to

\footnotetext{
${ }^{50}$ Davis, supra note 2, at $45-46$.
} 
observers. Equally important, they can perform essential data reduction at the same time, analyzing the significance of concomitant trends of different aspects of body functions to determine whether they are compatible. On occasion, those functions might be within acceptable limits individually but might be moving in directions that spell trouble.

Many elements of computer treatment systems, if not the entire systems themselves, might require clearance by a federal agency prior to regular use, in much the same manner as the Food and Drug Administration clears drugs. ${ }^{57}$

At the present state of the art, computer treatment systems very likely will be provided under the auspices of hospitals. They resemble the services traditionally furnished by those institutions, and the information they will collect would be very useful to the hospital staff for research and medical audit purposes as well as to attending doctors. It seems improbable that the operation of those systems would be the type of activity an independent entity would undertake to offer to doctors. However, cooperatives of smaller hospitals or other organizations might actually run the systems. Under the circumstances, any charges for system use probably will be billed by the hospitals directly to the patients.

Since practicing doctors are responsible for the conduct of the activities in which treatment systems would be included, the major initiative for the use of such systems will come from them. While doctors still will have to be satisfied that the treatment systems are technically satisfactory, when using them they will not be confronted, as in the case of general diagnostic systems, with possible adverse reflections on their competence in the minds of their patients. On the contrary, such use probably will evoke favorable reactions because they appear to be modern medical tools. Patients, on the other hand, very likely will have little occasion to prod their doctors to use the new devices in the way they might induce resort to a consultant.

\section{B. The Doctor's Malpractice Liability}

The liability exposure of a doctor prescribing use of a computer system in therapy will vary widely, depending upon the type of application. With all types of systems,

\footnotetext{
${ }^{57}$ An administration bill to expand the Food, Drug, and Cosmetic Act to authorize the setting of standards for medical devices (other than those intended solely for diagnostic use) was introduced on June 8, 1967. H.R. 10726, 90th Cong., Ist Sess. (1967). This bill would extend the safety, reliability, and effectiveness provisions of the Federal Food, Drug, and Cosmetic Act, now applicable to drugs, to medical devices. Thus, the Food and Drug Administration would have the authority to require that medical devices be safe, reliable, and effective, both in their uses and in terms of the claims made for their use. Computers, their ancillaries, and their programs might well be considered "medical devices" when used in a medical or hospital application. The FDA has identified categories of devices it would be litely to regulate if H.R. ro726 is enacted. Electronic News, Oct. 23, I967, at 34, cols. I-2.

Previously, on February 27 , 1967 , a bill was introduced to establish an independent study commission to determine the need for and the extent of federal regulation of medical devices and cquipment. H.R. 6165, 9oth Cong., Ist Sess. (1967). Under this approach, direct government action would presumably be postponed until the commission recommended methods for determining minimum performance standards and feasible methods for federal regulation.
} 
injury might be caused by the attachment of sensors and other equipment to the patient's body. Harm also might result from reliance on erroneous information collected by a data logging or monitoring system, from malfunctioning of a therapy system otherwise used in a proper situation, or from use of a therapy system where inappropriate.

In selecting and applying those devices, the doctor must use the regular degree of care expected of him in performing his work. He normally would not have to examine them for latent defects, ${ }^{58}$ but should be on the alert for information on problems experienced with particular devices. If medical systems are cleared by a government body, such use authorization for a device that caused harm very likely would support a doctor's contention that he exercised due care in selecting it for a proper application, until he actually had or should have had knowledge that it was deficient..$^{59}$ Similarly, if such clearance is required, the regulatory body well might require statements by the manufacturers of situations in which use is contraindicated. ${ }^{60}$ Failure to observe those limitations of which he should have been aware would expose a doctor to liability for resulting harm. Manufacturers undoubtedly would have to use methods for publicizing device limitations at least similar to those followed with respect to drugs, which largely involve distribution of literature through detail men and inclusion of notices with the products. ${ }^{61}$

Despite necessary recognition of possible adverse experiences, medical data logging and monitoring systems have so many potential advantages to patients that eventually they will be recognized items in the medical armamentarium. Then, use of such devices, when available in particular situations, very likely will constitute due care and a failure to take advantage of the proper one would be malpractice if harm resulted. Although closed loop therapy systems seem to be further in the future, they also might achieve the same status.

There is a real danger that doctors' concerns over malpractice suits might discourage them from pioneering in the use of closed loop computer therapy systems, thereby delaying the introduction of many devices that could be very beneficial in rendering medical care. The present standard of legal care supports such conservatism, relying as heavily as it does, in the case of new techniques, on the extent to which the particular approach is used by an appropriate segment of the profession. The importance of facilitating the adoption of computer devices that substantially advance medical practice requires close attention to the

\footnotetext{
${ }^{63}$ Hine v. Fox, 89 So. $2 d$ I3 (Fla. I956); cf. Smith v. American Cystoscope Makers, Inc., 44 Wash. 2d 202, 266 P.2d 792 (1954). Probably the more professional and ostensibly qualified is the organization operating the system, the less the doctor would be expected to investigate the details of its system design and programming.

${ }^{80}$ See Lewis v. Baker, 243 Ore. 317, 413 P.2d 400 (I966).

${ }^{\circ}$ See id.

${ }^{1}$ See generally Ruge, Regulation of Prescription Drug Advertising: Medical Progress and Private Enterprise, in this symposium, p. 650. As indicated in note 82 infra, manufacturers might use a constantly updated computer information system for the purpose of alerting doctors to device limitations.
} 
elimination of any such inhibition. The situation is quite different from that with respect to other types of medical devices, which have been much simpler in operation and commensurately more limited in their impact on treatment. There are a number of possible solutions to the problem.

If doctors are willing to take the initiative, they might try to get consents from patients, at least until use of a device has become accepted medically. ${ }^{22}$ The importance of promoting medical progress would seem to warrant serious consideration of such a step. Of course, it would be feasible only if the consent were carefully drawn to apply only to the particular measure and if there were adequate pretesting of the device.

An alternative approach might be for system manufacturers to undertake to indemnify doctors for any out-of-pocket loss from using devices as recommended, where such consents are not secured. This probably would be unacceptable to doctors because understandably they would prefer to avoid the risk of malpractice claims, with resultant damage to their reputations.

The most satisfactory solution would be to change the test of malpractice liability. Such a change probably could not be accomplished through the courts, as a practical matter, because of the hazard in exposure to litigation until a revised standard is adopted. However, it might be reasonable to try to secure state legislative relief for doctors with respect to devices that have been cleared by a federal agency. In effect, such a step would substitute federal clearance for wide professional use. That approach would not deprive patients of proper recovery in the event of harm since the doctor should remain liable for misuse of a cleared machine system and the manufacturer would be subject to suit if its product was defective in design or operation. $^{\mathbf{6 3}}$

Through actual operation rather than as a matter of law, the performance of machine data logging could affect the liability of doctors, both favorably and adversely, by making valuable evidence available in many malpractice situations not involving computer systems directly. It is reasonable to assume that logging results will be retained in patient records. They will be more extensive, and possibly even more objective, then records kept by many doctors personally. Computer system records also will provide essential information, with possibly similar results in many cases, to hospital medical audit units, such as tissue committees, that maintain oversight over the practices of staff doctors. ${ }^{64}$

\footnotetext{
${ }^{02}$ To be valid where the technique is new and hazardous, consent must be "informed." Natanson v. Kline, I 86 Kan. 393, 350 P.2d 1093, rehearing denied but opinion explained, I87 Kan. 186, 354 P.2d 670 (1960). Such consent covers only the risks inherent in the treatment and not any negligence of the doctor in selecting or administering it.

${ }^{63}$ Such is the case with respect to cleared drugs. Lewis v. Baker, 243 Ore. 317,413 P.2d 400 (I966).

o6 Louiseli \& Williams, para. 2.04, at 2x; Appleman, The Preparation of Medical Malpractice Cases, in 12 Trial and Tort Trends 452, 466 (M. Belli ed. 1962); Derrick \& Wilber, The Electronic Computer and Developing Concepts of Patient Monitoring, INr's ANesthesiology Clinics, May 1965, at 507.
} 


\section{The System Operator}

\section{Negligence}

A patient could be interested in suing the business entity operating a treatment system for negligent harm caused by system malfunctioning, especially if his doctor was not negligent in using the system. The operator probably would be negligent if the negligence of any independent producer of any elements of the system, including the equipment manufacturers, the system designer, and the programmer, caused the harm. In view of his direct involvement with system use, particularly his payment for it, the patient should have no difficulty with the privity requirement, where it still exists. Occasionally, he might run up against the charitable or governmental immunity doctrine, however, since hospitals can be expected to be the operators. $^{65}$ Furthermore, the patient might have difficulty in proving negligence if harm results from the operation, in the recommended manner, of a system enjoying clearance by the cognizant federal agency, before the operator has had the opportunity to learn of weaknesses uncovered subsequently. ${ }^{66}$

On the other hand, a hospital that does not have a computer therapy system that would be appropriate for a particular problem has the legal duty to transfer the patient to one that does. ${ }^{67}$ More realistically, hospitals worthy of the name must keep abreast of technological developments in medicine by making machine assistance available at their facilities when it is reasonable to do so.

\section{Strict Liability}

Where harm results from system use, patients would prefer to rely on the strict liability approach in suing the hospital to avoid the burdens of proving negligence, especially if there was compliance with official clearance requirements. By running an information processing machine that produces output information, the operator might be considered a manufacturer and hence responsible for harm resulting from the use of its products, regardless of fault. Although the delivery of information is less obvious in a closed loop therapy system, it does occur, if that factor is an essential ingredient for liability. Alternatively, the operator might be regarded as an element in the chain of distribution of the equipment, much as the lessor of an automobile, ${ }^{68}$ and be liable on that basis. Although courts have been reluctant to impose strict liability on hospitals, the situation well might change. ${ }^{69}$

\footnotetext{
${ }^{\text {or }}$ An entity established by a group of hospitals cooperatively might not enjoy the immunity of its sponsors, just as it is considered not to enjoy their tax-exempt status without legislation. A bill now pending would confer such status. S. 2315, goth Cong., Ist Sess. (1967).

${ }^{\circ 0}$ See Lewis v. Baker, 243 Ore. 317, 413 P.2d 400 (1966).

${ }^{o r}$ See Carrasco v. Bankoff, 220 Cal. App. 2d 230, 33 Cal. Rptr. 673 (I963):

${ }^{08}$ See Cintrone v. Hertz Truck Leasing \& Rental Serv., 45 N.J. 434, 212 A.2d 769 (1965) (lessor liable to helper of lessee's driver).

${ }^{\circ 9}$ See cases cited note 33 supra.
} 


\section{The System Manufacturer, Designer, and Programmer}

\section{Negligence}

Where treatment systems are provided by hospitals, injured patients frequently might seek to sue the manufacturers rather than the hospitals, even if fault must be proved. The handicap of charitable or governmental immunity would be a reason for such a choice. In addition to the requirement of proper design and manufacture, the manufacturer's duty of due care would require it to notify operators and users of any propensities of its product to cause harm of which it knew or should have known. ${ }^{70}$

Independent designers and programmers of treatment systems would be subject to liability for negligence similar to that for faulty design and programming of diagnostic systems.

\section{Strict Liability}

Patients more likely would seek recovery from system manufacturers on the basis of strict liability. Since negligence is not relevant, clearance by a federal agency should not bar recovery if a defect existed nevertheless. ${ }^{11}$ The considerations discussed in connection with such liability in the use of computer diagnosis systems would be pertinent to treatment systems. However, the propriety of tempering the strict liability rule with respect to the medical information stored in computer systems, as discussed with respect to the liabilities of operators and manufacturers of diagnosis systems, seems to be even more pertinent to therapy applications. In any event, strict liability applies even where products are not defective, if particular directions or warnings required for safe use are omitted. ${ }^{72}$ Where strict liability is applicable, the system manufacturer is exposed to such liability notwithstanding the impossibility of anticipating the occurrence of harm, a particularly important consideration in view of the difficulties in designing computer systems. ${ }^{73}$

Independent designers and programmers may also be subject to strict liability, just as designers and programmers of diagnostic systems.

\section{Injury to Doctor's Reputation}

A doctor's professional reputation could be harmed by his use of a defective computer treatment system. Since he probably would be on the staff of the hospital

${ }^{70}$ Harmon v. Plapao Laboratories, 218 S.W. 7or (Mo. App. 1920); Cleary v. John M. Maris Co., I73 Misc. 954, 19. N.Y.S.2d 38 (Sup. Ct. 1940); Pariser v. Wappler Elec. Co., 145 Misc. 315, 260 N.Y.S. 35 (Sup. Ct. I932); LaFrumento v. Kotex Co., I3I Misc. 314, 226 N.Y.S. 750 (New York City Ct. I928). Food and Drug Administration regulations require warning labeling for medical devices that must be operated under a doctor's supervision because they have a "potentiality for harmful effect." 2I C.F.R. \$ r.106(d) ( 1967 ).

${ }^{71}$ Lewis v. Baker, 243 Ore. $3 \times 7,413$ P.2d 400 (1966).

${ }^{72}$ Crane v. Sears Roebuck \& Co., 218 Cal. App.2d 855, 32 Cal. Rptr. 754 (1963); LaPlant v. E. I. duPont de Nemours \& Co., 346 S.W.2d 231 (Mo. 196r).

${ }^{73}$ Gottsdanker v. Cutter Laboratories, 182 Cal. App. 2d 602, 6 Cal. Rptr. 320 (r960); Green v. American Tobacco Co., 154 So. $2 \mathrm{~d}$ 169 (Fla. I963). 
making it available and might even have been involved in selecting the particular system, such a doctor more likely would sue the system manufacturer than the hospital. That type of claim has already been discussed in connection with diagnosis systems. $^{74}$

\section{Misbranding}

Although equipment used in medicine is not subject to the clearance requirements of the present Food, Drug, and Cosmetic Act, the proscriptions against misbranding do apply to it. ${ }^{75}$ That legal weapon might be used against manufacturers that do not provide adequate warnings of limitations in their therapy systems. ${ }^{76}$

\section{IV}

\section{Patient Simulation by Computer}

\section{A. Nature of Patient Simulation Systems}

As in the case of computer simulation applications elsewhere, simulation systems in medicine will exist in two different forms-physical models and mathematical models.

Physical models will consist of computer-linked mechanisms that respond to medical procedures in the same manner as the real human system. For example, already a dummy of a human being is being used for teaching purposes. Among other things, it reports, through its computer, when and in what respects injections have been given incorrectly. A similar device for training anesthesiologists has been constructed. It includes a manikin that manifests, in real time, lifelike reactions to medical procedures and a device that prints out reports. ${ }^{77}$

In the mathematical model approach, in contrast, the functioning of the genuine item is described by a series of mathematical formulae that can be manipulated by computer in terms of input data representing a particular situation. Such models probably will be available at least for a number of human organs. Using those models, adjusted (by the input data) to reflect the actual condition of the organ under consideration, a doctor should be able to pretest the results of various types of treatments and the effects of new drugs and to determine such information as the status of a disease in a person and the consequences of lack of treatment. Such a tool has utility in medical research, teaching, and especially treatment. This type of model system consists essentially of digital computers and mathematical models reduced to programs.

The physical simulators will be made available to students by medical schools. The mathematical model simulation systems very likely will be provided to

\footnotetext{
"Tee p. 687 stipra.

t5 2 I U.S.C. $\$ \S 32 \mathrm{I}(\mathrm{g}),(\mathrm{h}),(\mathrm{n})$ ( 1964 , Supp. II, I965-66).

${ }^{70} 2$ C.F.R. $\$$ I.I06(d) (1967).

${ }^{77}$ Loberman, Computer Control of a Manikin for Anesthesiological Training, in CouncrL to AdvanCE Programame, Proceedings Fall 1967 (Computer Control Division, Honeywell Inc., forthcoming).
} 
students by their medical schools, to practicing doctors by their hospitals and possibly by other entities, and to research workers by their particular companies or other organizations. Patient charges would be involved only where model systems are used in treatment. They probably will be handled the same as for laboratory work.

As with treatment systems, the major initiative to use mathematical model systems in rendering medical care will come from practicing doctors. The assistance in pretesting contemplated treatment will be beneficial in performing normal medical work. Undoubtedly, patients will consider the tool to be an appropriate aid to doctors, and resort to it will not be construed as an admission of professional weakness, as distinguished from general diagnosis systems. Since charges for such service will be quite low and patients will pay them, doctors will have no economic objection to their use.

Where mathematical models are used with computers in connection with treatment, the results probably will appear on a computer printout along with the patient's name and file number, the input data reflecting the particular condition noted and submitted by the doctor, and identification of the program (and hence model) utilized. That tangible information properly would be included in the patient's record.

Although physical simulation machines will be located where they are used, the mathematical model devices will be able to be utilized from a substantial distance, by various economical telecommunications means.

Despite the fact that mathematical simulation systems will not be connected to patients' bodies, there is a good chance, since doctors will rely on them in therapy, that efforts will be made to subject them to advance clearance requirements. Against that step, it might be argued that such an approach carried to its logical conclusion would require similar clearance of medical treatises. On the other hand, it could be contended that books present relatively complete information for the using doctor to evaluate, whereas complex machine systems generally have to be utilized with considerable reliance on the representations of the manufacturers or operators. - The legal liabilities of operators, manufacturers, designers, and programmers of simulation systems are the same as in the case of computer treatment systems, which have already been discussed. Thus, the following treatment of simulation systems is limited to their significance for the physician and patient.

\section{B. The Doctor}

\section{Malpractice Liability}

Where a simulation system used in therapy produces incorrect information and a patient is harmed as a result, the doctor would be liable for malpractice if he relied on a technique not yet recognized by his colleagues or cleared by a cognizant government agency. Once either of those circumstances has occurred, the doctor probably 
would escape liability for resulting harm, unless he actually had or should have had reason to doubt either the value of the system for the particular purpose or the output received but used it nevertheless.

On the other hand, when a simulation technique is accepted by the profession, a failure to use it where it is available and where there is no economic barrier to its use probably would be actionable if harm to the patient could have been avoided in that manner. As indicated, telecommunications can make simulation service facilities located at a considerable distance available as a matter of fact. However, proof of liability could be difficult, unless the information about the patient that the doctor should have submitted for processing appears in the patient's record. If such information is known, what the computer system would have responded usually can be determined accurately.

\section{Access to Hospital Facilities}

Despite the unavoidable (to a lawyer) adversions to harmful involvement with computer medical systems, such systems promise great positive contributions. In fact, the doctor's duty of due care undoubtedly will require his increasing use of such systems. Since most types of systems very likely will be operated by hospitals (so-called private as well as admittedly public or, more properly, governmental), attention will tend to be drawn to the doctor's freedom of access to the new services. The initial reaction might be to consider that facet as a matter of the doctor's right of admission to hospital staffs or visiting privileges, which right appears to exist with respect to government hospitals but not private ones. ${ }^{78}$ However, it actually might be entirely sufficient merely to make available to all doctors the services themselves that do not entail hospitalization of the patient. Such services would include both types of diagnosis, simulation in therapy, and recommended therapy routines, and might also include record-keeping for doctors' practice outside hospitals.

\section{The Patient's Privacy}

The availability of physical simulation models for teaching medical students eventually might provide the basis for the enlargement of the right of privacy of hospital patients to spare them from serving as subjects in routine teaching activities. With the broadening of the definition of that right generally, it reasonably could be contended that patients should not be subjected to observation and treatment by medical students any more than absolutely necessary for training purposes. ${ }^{79}$ Certainly, the long accepted distinction that indigents should be available as teaching

\footnotetext{
${ }^{78}$ See Horty, The Legal Right of Physicians to Hospital Privileges, 44 CHI. B. RECORD 373 (1963).

${ }^{70}$ Prior to Medicare and similar programs, involvement as teaching subjects was a problem almost cxclusively of the poor. See generally Handler \& Rosenheim, Privacy in Welfare: Public Assistance and luvenile Justice, 3I LAw \& ConteMP. Prob. 377 (1966), for a discussion of encroachments on the privacy of the poor.
} 
subjects because they do not pay for medical care has even less validity when simulation devices can be used at reasonable cost. ${ }^{80}$

\section{V}

\section{Hospital Computer Record Systems}

\section{A. Nature of Hospital Computer Records Systems}

Hospitals are starting to adopt computers for a wide variety of uses, ranging from ordinary accounting to the maintenance of records on patients, operations performed, and other matters. ${ }^{81}$ In the application involving patients' records, the usual information about each patient is kept in digital form so that it can be called out and supplemented by nurses and doctors at input-output terminals. Machine management of such information can remind nurses of medication schedules and check on their compliance and can screen doctors' orders and contemplated action against contraindicated medicines and procedures specified in the record. Similarly, it is possible to verify medication prescriptions against a general file of information, for proper spelling, dosage, and application. ${ }^{82}$ Patient records kept in machinereadable form also can be examined easily for medical research purposes and to maintain oversight by hospital medical audit committees over treatment rendered by staff doctors. The other records could include not only logs of operations but also tissue committee reports. ${ }^{83}$ In addition, they provide a source of evidence for litigation. ${ }^{84}$

The furnishing of hospital record systems will be the responsibility of the hospitals. Their cost will be defrayed through normal charges for hospital service rather than by specific fees. Their use will be routine once they are adopted and will not depend upon the discretion of doctors.

\footnotetext{
${ }^{80}$ Such situations could be considered to be improper intrusions, which Professor Bloustein believes to be illegal because they constitute "a blow to human dignity, an assault on human personality," and are "demeaning to individuality." Bloustein, Privacy as an Aspect of Human Dignity: An Anstver to Dean Prosser, 39 N.Y.U.L. Rev. 962, 974 (1964). Cf. Inderbitzen v. Lane Hosp., 124 Cal. App. 462,12 P.2d 744 (I932); DeMay v. Roberts, 46 Mich. I60, 9 N.W. 146 (r88r) (improper intrusion during childbirth).

${ }^{81}$ Eventually, when remote access is routine, hospitals might offer to keep the regular patient records of doctors not involving hospital treatment. In using such services, doctors should satisfy themselves that unauthorized access to those records is prevented in order to avoid legal exposure. See Note, Action for Breach of Medical Secrecy Outside the Courtroom, 36 U. Cin. L. Rev. I03 (1967); Note, Medical Practice and the Right to Privacy, 43 Minn. L. Rev. 943 (1959); cf. Boyd v. Wynn, $286 \mathrm{Ky} .173,150$ S.W.2d 648 (r94r).

${ }^{82}$ It is possible that a service might be offered, either as a commercial venture or as a public service of pharmaceutical manufacturers or others, for clearing specified medicines, in light of current information, for use with indicated symptoms or diagnosed conditions. The output could include warnings of limitations of uses, such as are included in packages of medicines.

${ }^{83}$ Appleman, supra note 64 , at 466 .

${ }^{84}$ Morris, Hospital Computer in Court, M.U.L.L., June 1963, at 6r; letters from Gerard Salton' and R. Crawford Morris, M.U.L.L., March 1964, at 34 (hospital computer system searched 6.25 million patients' charts in 25 minutes and located chart that disclosed that plaintiff's expert witness previously made same erroneous diagnosis as did defendant). Tissue committee reports might not be admissible in cvidence, Judd v. Park Avenue Hosp., 37 Misc. 2d 6r4, 235 N.Y.S.2d 843 (Sup. Ct. 1962), affd, 235 N.Y.S.2d I023 (App. Div. I962), and Calif. Evid. Code $\$$ II $_{5} 6$ (West 1966), but are subject to discovery in California. Id. See The Tisste Committee, 160 J.A.M.A. 1238 (1956).
} 
When patient records can be handled in machine-readable form, reasons of economy suggest the elimination of most traditional paper records, many of which contain authorizing and validating signatures. Substitute means for signifying authorizations and validations by doctors in ways compatible with digital systems undoubtedly will be devised, since it is unlikely that either their elimination or the expense of continuing to use customary records for that limited purpose can be accepted. Paper consent, personal property acknowledgment, and similar forms signed by patients undoubtedly will continue for some time.

Use of records accessible remotely entirely by machine introduces a threat to the privacy of patient information. In traditional systems, the identity of each person requesting file data is known and his authority to receive the particular material can be verified. Efforts are being made to devise foolproof recognition techniques for use with machine inquiry terminals in all types of systems. ${ }^{85}$ Hence, the preservation of privacy of medical information is a problem present in many types of computer systems that are shared by many persons. Solution of the general problem certainly will fill the need in the hospital area. However, since breach of a hospital system offers less valuable returns than check or credit forgery, less rigorous identification means probably will be acceptable.

On the other hand, maintenance of patient records by computer facilitates the distribution of information already required by or useful to a wide variety of outside agencies, such as vital statistics bureaus (births and deaths), police departments (gun wounds and other foul play ${ }^{86}$ ), local, state, and national public health units (crippled children, ${ }^{87}$ communicable diseases, ${ }^{88}$ and drug addiction), Social Security Board (births and deaths), and the Internal Revenue Service and other tax authorities (deaths) ${ }^{89}$ That information can be disseminated automatically in either digital or printed form. Wherever appropriate, the patient or his representative should be informed of the making of such reports. Such notification can be given easily by having a computer print up the letters.

The efficiencies and other advantages achieved by computerization of hospital records should be available for equally important patient records kept by doctors in their own files. To achieve such advantages, hospitals might offer to keep those files for a fee, when telecommunications means with remote terminals are available economically for doctors' offices. Under such an arrangement, consideration should

\footnotetext{
${ }^{85}$ Ware, Security and Privacy In Computer Use, in Am. Federation of Information Processing Societies, 1967 Spring Joint Computer Conference Proceedings 279; Petersen \& Turn, System Implications of Information Privacy, id. at $29 x$.

${ }^{30}$ E.g., MASS. ANN. LAwS ch. II2, § I2A (1965).

${ }^{87}$ E.g., ConN. GeN. Stats. ANN. $\$$ Ig-2I (Ig60); Mass. ANn. Laws c. III, $§ 67 \mathrm{E}$ (Supp. I966) (statefurnished form required).

${ }^{88}$ E.g., Conn. Gen. STats. ANn. $\$$ I9-89 (Ig60); Shoemaker v. Friedberg, 8o Cal. App. 2d 9ri, I83 P.2d 318 (x947).

80 The last two are suggested as possible information items that soon will be deemed to be useful, respectively, to trigger the issuance of Social Security numbers and to record the deaths of persons from whom income tax returns are expected because their names appear on the Service's master list.
} 
be given to the extent to which the doctor's records should be processed similarly to the hospital's, such as for the automatic reporting of particular events to government agencies.

\section{B. The Hospital}

\section{Negligence}

If a hospital adopts a computer record-keeping system that permits harmful errors to be made in the patients' files, it probably would be liable for negligence, unless shielded by charitable or governmental immunity. At the present state of the computer art, it is unlikely that it would be reasonable to choose a system that is errorprone. Proof that a system is so vulnerable would be much easier if it is computerized than if it is operated solely by people, because of the availability of more complete documentation for machine systems. In fact, the requirements of due care, if not professional responsibility, probably would make it advisable to include in such a system the technique for monitoring the administration of medications since such a measure is feasible and its cost would be relatively low.

As was observed in other connections, computer use for recordkeeping could minimize the occurrence of negligent acts, thereby reducing legal liability in practice by preventing harm. For example, machine verification of patient identity, a routine but highly reliable operation, would avoid the insertion of data, such as clinical laboratory reports, in the wrong records. ${ }^{80}$

\section{Recordkeeping Requirements}

The hospital using a computer for record maintenance must comply with any legal and other requirements on documentation of treatment authorizations, laboratory reports, and other events, if it seeks to abandon traditional paperwork. Such requirements might be found in statutes, in rules adopted by professional bodies, ${ }^{01}$ or merely in practical legal precautions.

Particularly troublesome is the general requirement that hospital medical records ${ }^{92}$ and orders ${ }^{93}$ be signed by the physician. Designers of hospital systems are planning to have special code identifications for doctors used at input terminals, to be entered either through a keyboard or by an embossed wafer, like a credit card, in lieu of signatures, with the reasonable expectation that the requirement will be changed. In some cases, the acceptable physical forms of the records are prescribed

\footnotetext{
${ }^{90}$ This problem is discussed in Mills, stupra note 30 , at $64 \mathrm{r}$. A recent study disclosed that almost fifteen per cent of the medications administered in a particular hospital were incorrect. Barker, Kimbrough \& Hiller, The Medication Error Problem in Hospitals, I Hosp. Formulary Management 29 (1966).

91 JoInt Comm'N on ACcreditation of Hospitals, supra note 14, at 3-4.

92 Id. at 3; Dep't of Public Health, Commonwealth of Massachusetts, Licensure Rules and Regulations for Hospitals and Sanatoria 4 (1950).

${ }^{93}$ Joint Comm'n on Accreditation of Hospirals, Model Medical Staff Rules and Regulatjons 14 (1964).
} 
by statutes, ${ }^{94}$ which also will have to be altered. Fortunately, government and other authorities appear to be receptive to reasonable changes required for computer systems. ${ }^{95}$

The right of patients and others to inspect and secure copies of hospital records ${ }^{90}$ should not inhibit the adoption of computer record-keeping systems. Printing and cathode ray tube display techniques usually provided so that hospital personnel can read those records that are not legible visually probably will be entirely adequate for outsiders as well. In lieu of actual copies of the records, it usually should be acceptable to furnish visually legible conversions in the form of either printouts or copies of the displays. ${ }^{97}$

As a matter of mechanics, hospitals might have to explore the use of new numbering systems to identify patients in their records in order to minimize identification errors (and resulting liability) and to facilitate integrated use of recorded information. Computers can verify numbers much more efficiently than can people. For example, they can utilize self-checking digits to uncover transpositions and similar errors. If a universal numbering system is considered desirable for integration with other files, such as those of other hospitals, doctors, laboratories, or vital statistics bureaus, consideration might be given to the approach of the Internal Revenue Service, in which the Social Security number is used with the first four letters of the person's name.

\section{Evidence}

The maintenance of hospital records in forms unique to digital computer systems and unreadable by sight does not diminish their admissibility as evidence in litigation. If they otherwise meet the standards of business records, such records will be accepted by courts to the extent that their visually legible counterparts will be received, even if made expressly for the litigation. ${ }^{98}$ Of course, entry in a computer system will not improve the low evidentiary quality of recorded self-serving statements of the patient or his family on what occurred outside the hospital. ${ }^{99}$ However, much evidence generated in the hospital of the type that is of probative value will

\footnotetext{
${ }^{04}$ E.g., Mass. ANN. Laws c. III, $\$ 70$ (Supp. I966) (handwriting, print, typewriting, photographs, or microphotographs).

${ }^{0}$ For example, the Joint Commission on Accreditation of Hospitals has so indicated but insists that responsible persons be identified clearly. Letter from J. D. Porterfield, M.D., I Health Services RESEARCH IIg (1966). Oral communications of the writer with some state authorities are consistent.

${ }^{00}$ Conn. Gen. Stats. Ann. $\$ \S 4-104$, -I05 (I960); Mass. ANn. Laws c. III, $\$ 70$ (Supp. 1966); Wis. Stat. $\$ 269.57$ (1965).

${ }^{\circ 7}$ See Freed, Providing by Statute for Inspection of Corporate Computer and Other Records Not Legible Visually-A Case Study on Legislating for Computer Technology, 23 Bus. LAw. 457 (1968). Persons inspecting hospital medical records occasionally might want machine language copies for processing by computer on their own behalf.

os Transport Indem. Co. v. Seib, ${ }_{7} 8$ Nev. 253, I32 N.W.2d 871 (I965). See Freed, Computer Print-outs as Evidence, in 16 Ax. JUR. Proof of FACTs 273, 316 (1965); Freed, supra note 97.

${ }^{00} \mathrm{See}$ Sheary v. Hallock's of Middletown, Inc., I49 Conn. I88, I77 A.2d 680 (I962) (to be admissible, entry must be based on entrant's own knowledge or that of a person who has a business duty to transmit the information).
} 
be more accurate when it is collected and recorded either by machine or by people for a machine system.

\section{The Patient's Privacy}

Patients are entitled to protection from breaches of their privacy in the use of hospital record systems accessible widely. Hospitals must take reasonable measures to protect that privacy. ${ }^{100}$

\section{The Doctor's Malpractice Liability}

Computerization of patient records kept in hospitals and private practice should help doctors satisfy their duties to read prior records that are readily available and to warn patients of previous treatment that has been discovered to be harmful. ${ }^{101}$ Fulfillment of those duties can be onerous with respect to traditional paper records because of the mechanical difficulties of securing an earlier record from another repository and of searching through voluminous records. By making both measures relatively easy to perform, computer systems will reduce human barriers and the disposition to gamble.

The exposure of doctors to malpractice liability also will be reduced substantially by the operation of hospital record systems that monitor the administration of medication and other treatment measures against patient records and general standards. Although patient records in the traditional form frequently specify contraindicated treatments, their administration often occurs nevertheless, with adverse results, because of the normal difficulty people have in using those records. Rigorous machine review, such as against both the particular patient's history and the standard cautions of drug identity, dosage, and propriety for the illness, will uncover the errors before they can cause harm. On the other hand, the inclusion in patient records, as already indicated, of greater quantities of detailed medical information increases the likelihood that doctors guilty of malpractice will be held liable because more evidence will be available.

\section{Summary AND Conclusion}

The nature of medical practice can be expected to change substantially with the eventual widespread use of computer systems to aid in diagnosis, treatment, and administrative activities. The remarkably versatile machines will be used not only to help professionals perform their usual functions better but also to carry out procedures beyond the capabilities of people. In the adoption of the new tech-

\footnotetext{
${ }^{100}$ Cf. Tournier v. National Provincial \& Union Bank of England, [rg24] I K.B. $46 \mathrm{r}$ (under common law, bank is liable for damages to customer from nonprivileged disclosure of information).

101 Schwartz v. United States, 230 F. Supp. 536, 540 (E.D. Pa. 1964):

"The negligence here is not in [the medication's] installation, but rather in not having affirmatively sought out those who had been endangered after there was knowledge of the danger in order to warn them that in the supposedily innocent treatment there had now been found to lurk the risk of devastating injury."
} 
nology, there is substantial promise of improved medical care, of increased productivity of professionals, and even of lower costs in limited areas.

As in all phenomena of this nature, legal involvement is unavoidable. Hopefully, it will not represent a negative factor in the development and use of the technology. Fortunately, the requirements of sound business administration and responsible professionalism usually will influence the taking of appropriate steps in the design, construction, and use of computer systems in medicine to prevent harm. With the example of the manufacture and administration of drugs, however, there is no assurance of complete success, and lawsuits will be brought. The outcomes of such suits and their impact not only on the particular area but also on society generally will depend upon both the legal rules considered to be pertinent and how effectively they are applied.

Despite the considerable novelty of introducing engineering extensively into medicine, the possible legal transgressions are sufficiently similar in nature to legal involvement in other areas of society for existing, fairly general rules of law to be usable in substantially all situations. Those rules are essentially means for distributing the impacts of losses caused by mishaps. Their sound application to computer medical devices will depend upon how well lawyers and judges comprehend the very novel and highly complex technology involved. As frequently is true, factual aspects are of major importance in influencing the outcome of litigation through the selection of legal theories and the marshalling and evaluation of proof. Judges and lawyers must achieve a fairly deep understanding of the new technology because of its novelty and complexity. In defining legal duties respecting use of the machines, they must be able to attribute the appropriate strengths to them as well as to recognize their real weaknesses. Doctors as well as computer specialists have a major role in interpreting the technology for this purpose.

The introduction of computers into medicine probably will cause a shift among the entities currently exposed to legal claims. For example, as harm can be attributed to machines, patients will prefer manufacturer's strict liability to medical malpractice actions. Although doctors still will be subject to legal exposure, they have every reason, since computer systems promise substantial benefits in medicine, to undertake to use those devices that are carefully designed and operated. In most situations, applicable legal rules do not expose them to unreasonable legal risks in doing so and in many cases probably will favor such use eventually by making it an exercise of due care. As a practical matter, furthermore, use of computer systems should reduce the risk of malpractice claims by preventing the occurrence of harm. However, it must be recognized that, by collecting medical information more effectively, such systems can make it easier to spot and prove some types of malpractice that do occur.

Some few changes in legal rules may be advisable. For example, with respect to therapy systems, where the test of malpractice might cause doctors to be unduly 
conservative in adopting valuable machine help despite the fact that it has met federal standards, a conscious effort should be made, probably through state legislation, to create a more favorable legal climate without sacrificing patients' rights. While protecting the interests of patients, which are primary, such a step would remove a possible marketing handicap for manufactures whose products pass evaluations of objective official experts.

It is hoped that this discussion of some legal aspects of computer use in medicine identified at this relatively early stage will dispel unwarranted concerns over the impact of the law on the promising mechanization in that area and will contribute to the sound resolution of legal questions when they arise. 